\title{
Tibetan Legends in East Journey in the Late Middle Ages
}

\author{
Xiaomei Han \\ College of Foreign Languages, Qinghai University for Nationalities, Xining Qinghai, 810007, China
}

Keywords: Middle ages, Tibet, Legends, West.

\begin{abstract}
The most distant land most people can inspire feelings of longing and desire to explore. There has been described in numerous exotic with oriental features in the late middle ages in Western literature, where Tibet has become a very exotic oriental enclave. Strange customs of Tibet description greatly enhanced the allure of the West, for the later image of mysterious Tibet foreshadowed.
\end{abstract}

\section{Text}

The most distant land most people can inspire feelings of longing and desire to explore, "playing the role of a foreign model most suitable candidates are those most distant from us, we know little about peoples and cultures." [2] Distant stranger exotic mystery is the source, but also excited to explore the source of desire and imagination. "Exotic" is subject to the observer perspective of regulation. It is not per se exclusive oriental features, but given its characteristics in the West "discovered" and understanding of East process. From this perspective, the Western "discovery" processes is actually associated with the East and gradually make the exotic of the process, but also the "Oriental" gradually into the Western literary imagination schema process. To emphasize the heterogeneous culture as the main feature of the exotic has become mutual understanding, communication and exchange among different civilizations in a very important driving force. In a long historical period, missionaries, travelers, traders, conquerors adopted an active role exotic gatherers and disseminators. They blur from the initial performance of the exotic, to consciously and purposefully rendered exotic, exotic alien deliberately create images different from their own culture.

In Western literature describes numerous exotic with oriental features in Tibet has become a very exotic oriental enclave. Tibet hearsay difficult to trace all the description greatly enhanced Tibet Westerners temptation. In these novels the narrator, the allure of the West Tibet is mainly from the following two aspects.

The first is the strange customs of Tibet, in the Marco Polo described the Tibetans will own these beautiful girls dedicated to outsiders:

This area, a kind of popular scandalous custom, people do not want to marry a virgin virginity, on the contrary, the idea to marry the woman who in the past had flesh and many heterosexual relationships. The reason why such a scandalous custom prevails, the result can only say that the blind worship of Buddhism. They think that this behavior is loved by God, and believe that no lover of a woman is worthless. [7].

In medieval secular life is a very vague and neutral sensitive topic, the Church also condemned sexual relations outside marriage, and is located in the hinterland of East Tibet openness towards sex will undoubtedly become catches the eye of an important message. [7]

Secondly, another factor of Western Tibet is full of temptation is witchcraft. "In the local (Tibetan) people, you can find the best wizards. They do come from the law, there is rage and lightning split thunder skills, this magic ever-changing, a lot can be turned into magical visions and miracles, but these miracles It was unprecedented, unheard of. "[7] In the "Odoric' s travels", it also mentioned 
these magical witchcraft," filled with the magic of wine golden cup flying the air, ready to drink to the person's mouth. "[5]

In Mandeville's Travels, the ability of witches are further exaggerated their magical wand, almighty. At the banquet, "they fell from the sky, bringing a bright, like the sun, the moon shining everyone. Then the dark, pitch dark. Then came the day, the sun shone pleasant. They bring the world the most beautiful girl dancing, holding a golden cup filled with other girls of different animals' milk, lords and ladies respectfully handed people to enjoy. "[9]

Beautiful girl and full of oriental magic wizards such exotic described as Europeans get a first impression of the orient. This first impression of the East have a lasting impact. It created the image of Tibet, after centuries of influence can not be underestimated.

Exotic otherness discourse as the construction, not always in a face appears. Medieval Europe to describe not only the stagnation of Tibet in a simple idealized description. Tibet image is sometimes presented as a distinct other side. In this narrative, the Tibet's most striking is its "absurd and horrible customs", the following described in Hubei Doric's Travels:

I arrived at a place called Tibet of the country ...... woman pigtail hair into a hundred pieces, and they have two long, such as wild boar teeth. This state of their other fashion is. If the father died, the son said: "I want to mourn my father"; and he put the state's monks, monks, musicians, as well as relatives and friends who remain. They happily transport the body to the outskirts. They prepared a large table, the table monk cut off his head, and then head handed his son. Son and all the people sang carols for the dead read by many. Then the monk body into pieces, in doing so, and then they all got into the city, walking and praying for him. Thereafter, the falcon flew down from the hills, depicting his piece of meat, put it away. Then all the people shouting, said: "!! Look at this man is a saint because Condor to take him to heaven go," so his son that he is very decent, because his father was this eagle happy way away. So he took his father's head, immediately put it cooked, and eaten. He put a bonnet made of glass, in memory of the deceased father. He and his family often religiously use it to drink. They say they can do for his father expressed great respect. [5]

This is probably the first Western Tibetan Funeral in the record, but was motivated by prejudice and cultural divide; the West is natural to the people of this place named "cannibal tribe." In the "Jean de Plan Carpin Mongolian travel" also has this narrative: "...... there is an incredible or, more correctly say is disgusting practices: If someone's father died, his son and all the relatives will divide the food. this is confirmed to us that the local situation. "[3]

In Marco Polo also mentioned a group of slovenly, form abominable, ragged dirty, vulgar rude people who like animals in addition to general life, frightening action, further cannibalism. After all criminals sentenced to death, they immediately carried away corpses, roasted with fire, and then expel human flesh. However, the natural death of the body, they will not eat. [7]

Likewise, a similar description is also found in Luke Rube travel, "there they are Tibetan; this nation has to eat their dead parents' customs. They piety, therefore, do not give their parents to find the tomb, but to them buried with their parents in the stomach ...... bonnet beautifully crafted cups, so every time by drinking this cup, they did not forget their parents in joy. it is a matter of seeing the man told me. "[6]

Although the narrators admit eating practices such appalling human body is not your own eyes can see, but listen to others described and recorded, but such descriptions continue to appear in many works, this narrative exhibit the Western world for the kind of complex psychological contradictions east. The "barbarians" exists often arouse missionary to "save" their religious impulse.

Thus, according to medieval Europe about Tibet there is very noteworthy information: account of Lamaism. They will compare Christianity and Lamaism, they found similarities and differences between, for the missionaries later provided a wealth of information.

Rub Luke Lamaism is the first to describe Westerners. He wrote: "All the (idol believers) Monks shaved head, wearing a red robe, and shaved since the day they abstain from meat, a hundred or two hundred live their flocks into the Japanese temple, swing. Two on the bench, then set up the altar where they sat, facing the altar, holding scrolls, sometimes put on the bench by the volume they are 
bareheaded in the temple, chanting in silence, keep quiet. .... they are holding a series of anywhere one hundred or two hundred beads, like us, like the rosary, mouth constantly read: "Amitabha. "One of them explained to me, that means:" God, you know. "They remembered, thinking about God, and expect God to give them a lot of reward." [6] For the teachings of the Buddha, Rube Luke only some very vague concept. "Idolaters" believe reincarnation theory and "all kinds of gods' existence. He learned that the killing Buddhists, and even kill a small insect is a kind of unforgivable sins.

Marco Polo Travels on the detailed description of the religion in Tibet, and reincarnation did explain very lively place, "they believe that the soul is immortal: Once a person dies his soul will be immediately on reincarnation. And the future status of the person in accordance with his lifetime of good and evil acts will get better or worse. If he is a poor man, but the behavior of nobility, then he will be reborn in decent women after birth to become a decent person. He reborn a second lady home, become a nobleman, he did so on the birth of grade backgammon, until God and merge together so far. on the contrary if he is a decent though people's children, but bad behavior, then his next life will become a clown, and ultimately become a dog, and will continue to fall, the more the lower down. "[7]

Thereafter Odoric also talked about Lamaism. "This town no one dared to kill any living creature, whether human or beast, it is because they are there to worship an idol piety. Abbas lived in the city Abassi, with they are the words of the Pope, he was the idol of all Christian princes, and his spending their way to supply their holy pension. "[5]

Here it emerged as the altar, scriptures, prayer beads, God, the Pope and the Holy Catholic pension system and a series of matches' terminology to explain and reflect Lamaism similarity between the two. When looking for footprints of Elder John has not stopped, full of Tibetan religious and Catholic has many similarities with the Tibetan religious missionaries naturally become one of the objects of most concern.

In addition, travel and locals also recorded some strange customs. Bailing guests mentioned the travels of this region rather peculiar phenomenon, "This nation has no chin whiskers, not only that, as we have witnessed it, they wearing one kind of instrument of iron, if occasionally two hairs grow out, they use this device unplugged "[3] pull misconduct mentioned in history:" they have some very strange this nomadic lifestyle, which is rare elsewhere: first, meat or other raw foods completely, do not know cooking. Second, they use meat instead of grain horses. "[8]

The reason except Tibet distant geographically, but also that it's difficult to access, "pull misconduct history" on the record of a miracle on Tibet, "that is to be Mughal children called" Asia Division "the Mountain Sickness ...... long after fell ill, the patient is unconscious, began to say nonsense, and sometimes could not speak, while palms and soles are swelling. At last, when the symptoms appeared, the patient will be at dawn to die between breakfasts ...... this disease was only foreign talent, Ust Tibetan locals never harm. "[8]

For the above travelers, missionaries really arrive over Tibet, most researchers held a negative attitude. Despite the lack of evidence that they personally enter Tibet, but this does not prevent them relayed through their own imagination and others construct having a "exotic" image of Tibet. When Tibetan culture in a significant difference appears in the vision of the West, the West continues to experience and express Tibetan exotic.

In fact, the exotic germination was almost simultaneous with war and the historical process of germination and exchanges between East and West, a series of historical events to promote the understanding of the East West. Wherein, the Yuan army expedition and the Crusades are two far-reaching historical events. Mongolian Yuan army expedition will affect the East to the West, the Mongol empire in the ancient Chinese civilization attracted a large number of businessmen and travelers went to China to open up their own businesses, but also greatly stimulated the Chinese send missionaries to the Holy See interest of. From the 11th century to the 13th century, the Europeans under the leadership of the Holy See launched nine Crusades, the Crusades did not change even though the eyes of the image of the east Europeans and fundamentally, but it greatly arouse Eastern European desire to explore, "the Crusades and stimulate the release of dynamism spirit help Europe 
for a new round of the 13th century found in the Oriental actions made preparations." [11]. Crusades conquest with the colonial nature of the conflict and to promote the integration of Eastern and Western civilizations further intensified and is reflected in the field of literature, writers increasingly interested in Oriental affairs, and a description of the exotic East is gradually increasing. Although this period all types of text description of the eastern half-truths and literary value is not high, but they will start the Eastern world shadowy outline presented in front of the Westerners.

\section{Acknowledgments}

This article is initial result of Qinghai University for Nationalities high-level personnel project

"Comparative Study of Chinese and Western Literature in Tibet Portrayal" (2013G014).

\section{References}

[1] Lach, Donald F. Asia in the Making of Europe. Chicago: The University of Chicago Press, 1965.

[2] Tzvetan Todorov. On Human Diversity: Nationalism, Racism, and Exoticism in French Thought.Trans.Catherine Porter. Cambridge, Massachusetts and London: Harvard University Press, 1998.

[3] Jean de Plan Carpin: Mongolia Travel Notes of Jean de Plan Carpin, translated by Han Baishi, Geng Sheng, Beijing: Zhonghua Book Company, 1985.

[4] Du Ping: Imagine Orient: Exotic and oriental image in English Literature Shanghai: Shanghai Foreign Language Education Press, 2007.

[5] Friar Odoric: Hai Tuen Travel notes, Odoric Shahrukh Mirza emissary China translated by He Gaoji. Beijing: Zhonghua Book Company, 2002.

[6] Rubruk: Rubruk’s east travel note, Rou Keyi, He Gaoji, Beijing: Zhonghua Book Company, 1985.

[7] Marco Polo:The Travels of Marco Polo, Chen Kaijun, Fuzhou: Fujian people's publishing house, 1981.

[8] Mierza Maheima Haidaer: Amon in Uighur history - Rashid, translated by Xinjiang academy of social sciences, national research institute, Urumchi: Volksverlag Xinjiang, 1985.

[9] John Mandeville: Travels of Mandeville, Guo Zemin, Shanghai: Shanghai Bookstore Publishing House, 2006.

[10]R. A. Rolf Alfred Stein: Tibetan civilization, Gen Sheng, Lhasa: Tibet academy of social sciences, 1985.

[11]Donald F. Lach. Asia in the Making of Europe, Volume I, The Century of Distory. Book I. Chicago: The University of Chicago Press, 1965. p.24. 